\title{
SOCIOECONOMIA E PERCEPÇÃO AMBIENTAL DE PESCADORES ARTESANAIS EM UMA COMUNIDADE DO MARANHÃO
}

\author{
Giovanna Santos de Souza ${ }^{1}$ \\ Maria Gracelia Paiva Nascimento² \\ Ruceline Paiva Melo Lins ${ }^{3}$ \\ Ivanilza Moreira de Andrade 4
}

Resumo: Objetivou-se avaliar o perfil socioeconômico e a percepção ambiental dos pescadores artesanais do município de Água Doce do Maranhão sobre a qualidade da água do rio Água Doce. Os entrevistados possuem condições básicas de moradia, acesso ao abastecimento de água e coleta de lixo. O rio foi definido como importante fonte de alimentação, sobrevivência e sustento, com água considerada de boa qualidade, sendo sua coloração apontada como principal indicador. O uso de apetrechos de malha reduzida foi associado à diminuição da quantidade e baixo rendimento do pescado capturado. Observou-se a necessidade de ações de sensibilização ambiental capazes de contribuir com a manutenção da qualidade do rio e dos estoques pesqueiros da região.

Palavras-chave: Delta do rio Parnaíba, Pesca artesanal, Qualidade da água.

\footnotetext{
'Universidade Federal do Piauí-UFPI, Teresina-PI, Brasil. E-mail: gih.ssouza@gmail.com, Link para o Lattes: http://lattes.cnpq.br/4537054549888152.

2Universidade Federal, do Piauí-UFPI, Teresina-PI, Brasil. E-mail: graceliapaiva@gmail.com. Link para o Lattes: http://lattes.cnpq.br/8351379531181067.

${ }_{3}$ Universidade Federal Delta do Parnaíba-UFDPAR, Parnaíba-PI Brasil.

E-mail: rmlins@ufpi.edu.br. Link para o Lattes: http://lattes.cnpq.br/3327055945085150.

${ }^{4}$ Universidade Federal do Piauí-UFPI, Teresina-PI, Brasil.

E-mail: ivanilzaandrade@hotmail.com. Link para o Lattes: http://lattes.cnpq.br/7284717480828084.
} 
Abstract: The objective was to evaluate the socioeconomic profile and environmental perception of artisanal fishermen in the municipality of Água Doce do Maranhão, in relation to the water quality of the Água Doce river. The interviewees have basic living conditions and access to water supply and garbage collection. The Água Doce river was defined as an important source of food, survival and sustenance, with water considered to be of good quality, in which the color is considered the main indicator, of quality, changing mainly in the rainy season, at high tide and at the spring tide. The use of reduced mesh fishing nets was associated with a decrease in the amount of fish caught and lower income obtained from fishing. It was observed the necessity for environmental awareness actions who are to contribute for the maintenance the quality of the river and fishing stocks in the region.

Keywords: Artisanal fishing, Parnaíba River Delta, Water quality.

\section{Introdução}

A atividade pesqueira, considerada uma das mais antigas ações da humanidade e que compreende desde o processo de captura até a comercialização do peixe, confunde-se com o modo de vida dos pescadores por representar mais do que uma relação de compra/venda ou trabalho/lazer. Além disso, o conhecimento empírico que inúmeras gerações de pescadores obtêm por meio da percepção comportamental da natureza é resultado de trocas de experiências com o ambiente aquático (RAMALHO, 2019). Nesta vertente, a água não é apenas uma substância física e um recurso escasso, mas um complexo em que permeiam relações simbólicas, religiosas, culturais, emocionais, místicas e de respeito (DICTORO; HANAI, 2016). Entretanto, devido às alterações globais e agravadas pela ação humana, faz-se necessário uma análise crítica sobre as formas de como lidar com as consequências que interferem nos múltiplos usos e na qualidade do ambiente, tais como, elevação do nível dos mares, desoxigenação e acidificação da água, assoreamento da foz de rios, poluição, redução dos estoques pesqueiros com a pesca ilegal, conflitos, dentre outros (FOGAÇA et al., 2018).

As percepções dos pescadores sobre a qualidade da água do rio moldam suas práticas pesqueiras, e nesse contexto, necessitam ser analisadas de maneira integral, a fim de compreender as relações sociais, tecnológicas, econômicas e ecológicas como subsídios para a elaboração de políticas públicas para a conservação do ambiente, o desenvolvimento socioeconômico dos pescadores e para que a sustentabilidade possa ser alcançada (FEITOSA et al., 2019).

O rio Água Doce, no município de Água Doce do Maranhão, objeto deste estudo, assim como as demais áreas de estuário pertencentes à Área de Proteção Ambiental Delta do rio Parnaíba, no estado do Maranhão, é utilizado como via de acesso para a pesca, cata de caranguejo, mariscos, sururu e ostras, além de ser um ambiente favorável ao cultivo de camarão (PEREIRA et al., 2017). Próximo ao rio Água Doce são encontradas áreas de salinas, desativadas há 50 anos em função do aumento da fiscalização e da diminuição da rentabilidade, onde a vegetação está em processo de reestabelecimento. 
A região do Delta do rio Parnaíba possui características e particularidades que os estudos buscam conhecer e avaliar a partir da percepção e conhecimento sobre a pesca realizada por pescadores artesanais, onde cita-se: Garcia e Furtado (2016), Meireles et al. (2016, 2017), Cantanhêde et al. (2018), Feitosa et al. (2019), Nascimento et al. (2019) e Diniz et al. (2020). Alguns trabalhos realizados no Brasil, discutem as relações dos pescadores com a água como os de Dictoro e Hanai (2016), Dictoro et al. (2016), Carvalho e Santos (2019) e Santos e Souza (2019). Porém, não foram encontrados estudos abordando a percepção dos pescadores sobre a qualidade da água para o estado do Maranhão, o que reforça a necessidade de pesquisas que subsidiem trabalhos de Educação Ambiental, voltados para conservação e para o planejamento de exploração do ambiente aquático, minimizando os impactos antrópicos e possíveis conflitos sociais.

Portanto, com esse estudo, objetivou-se avaliar o perfil socioeconômico e a percepção que a comunidade de pescadores do município de Água Doce do Maranhão tem sobre a qualidade da água do rio Água Doce, visando subsidiar políticas de gestão e conservação para a região.

\section{Metodologia}

A pesquisa foi submetida e aprovada pelo Comitê de Ética e Pesquisa da Universidade Federal do Piauí (CEP/UFPI), com parecer consubstanciado de no 2.752.003, conforme exigido pelo Conselho Nacional de Saúde (CNS) na resolução nº66/2012, ao cadastro de acesso ao Patrimônio Genético/CTA de no AE57515 no Sistema Nacional de Gestão do Patrimônio Genético e do Conhecimento Tradicional Associado (SisGen), em atendimento ao previsto na Lei no 13.123/2015 e seus regulamentos e ao cadastro no Sistema de Informação em Biodiversidade (SISBIO), determinado pela Instrução Normativa ICMBio n 03/2014, no 67592-1.

O presente estudo foi desenvolvido durante o período de maio de 2018 a dezembro de 2019, na comunidade de pescadores residentes na sede do Município de Água Doce do Maranhão, estado do Maranhão-Brasil, que são associados à Colônia de Pescadores Z-78 (0250'23.0"S e 4206'59.8"W), fundada em julho de 2003, com o objetivo principal de exercer atividades de defesa de direitos sociais dos pescadores.

O município de Água Doce do Maranhão limita-se ao Norte com os municípios de Tutóia e Araioses, ao Sul com os municípios Araioses, Magalhães de Almeida e São Bernardo, a Leste com Araioses e a Oeste com Tutóia (IMESC, 2016). A altitude é de seis metros acima do nível do mar, com variação térmica entre $22,7^{\circ} \mathrm{C}$ e $31,6^{\circ} \mathrm{C}$ e condição climática com dois períodos distintos: um chuvoso, de dezembro a maio e outro seco de junho a novembro (NASCIMENTO et al., 2017). Os solos são do tipo Latossolo Amarelo, Podzólico Vermelho Amarelo, Areias Quartzosas, Gleissolos, Plintossolos, Solos Aluviais e Solos de Mangue que são formados pelo depósito de silte, 
areia e material orgânico trazido pelos rios (SANTOS et al., 2018). A vegetação está representada pelo complexo vegetacional da zona litorânea restinga, dunas e mangues (CORREIA FILHO et al., 2011). A densidade demográfica do município é de 26,13 hab/ $/ \mathrm{km}^{2}$ e população de 11.581 habitantes, conforme dados censitários do Instituto Brasileiro de Geografia e Estatística (IBGE, 2011).

Os cursos d'água do Município fazem parte da bacia secundária dos rios convergentes do litoral oriental maranhense que são a bacia do rio Preguiças e a do baixo rio Parnaíba (CORREIA FILHO et al., 2011). A sede do Município é margeada pelo rio Água Doce, que na ausência de comitê para enquadramento, é considerado, pela resolução CONAMA n 357/2005, um ambiente de classe I, cujas águas são destinadas, entre outros fins, à recreação de contato primário, à proteção das comunidades aquáticas, aquicultura e atividade de pesca. Suas águas são, pela referida resolução, consideradas salinas já que os valores médios de salinidade estão em torno de $34,47 \%$. O rio sofre influência dos processos costeiros de meso-maré semidiurnas, com amplitude de $3 \mathrm{~m}$ (PEREIRA et al., 2016).

Para presente pesquisa, o tamanho da unidade amostral foi calculado de acordo com Barbetta (2011) na Equação (1): $n=\frac{N * \frac{1}{E^{\prime}}}{N+\frac{1}{E^{\prime}}}$, onde $\mathrm{n}=\mathrm{n}^{\circ}$ de elementos da amostra, $\mathrm{N}=\mathrm{n}^{0}$ de elementos da população, $\mathrm{e}^{2}=$ erro amostral, $14 \%$ no caso deste estudo, sendo amostrados 103 dos 313 pescadores associados à Colônia de Pescadores Z-78 e residentes na sede do município de Água Doce do Maranhão. A técnica utilizada para apresentar a pesquisa e obter a confiança do informante foi a de "rapport" (BARBOSA et al., 2007). Após consentimento de participação na pesquisa, foi solicitada assinatura e, no caso dos pescadores não escolarizados, coletou-se a impressão digital junto ao Termo de Consentimento Livre e Esclarecido (TCLE) e entregue uma cópia deste ao entrevistado.

Formulário de entrevista semiestruturado (APPOLINÁRIO, 2012) foi aplicado individualmente (PHILLIPS; GENTRY, 1993), e utilizado o auxílio de gravador e diário de campo para coleta de outras informações (SILVA, 2000).

O formulário foi composto por 40 perguntas contemplando dados de atividades profissionais, condições de saneamento da região, estrutura de moradia e a percepção dos pescadores sobre a qualidade da água do rio Água Doce. A faixa etária dos entrevistados foi agrupada nas categorias jovens (18 a 24 anos), adultos (25 a 59 anos) e idosos (a partir dos 60 anos), conforme IBGE (2011). A identificação dos participantes foi mantida em sigilo e seus nomes não foram incluídos nas bases de dados, garantindo o anonimato e a confidencialidade da informação.

Os dados foram plotados e analisados no software Microsoft Excel 2019, onde as tabelas de frequência geradas indicaram a representatividade das respostas dos informantes. 


\section{Resultados e discussão}

A idade dos entrevistados concentrou-se entre 18 e 59 anos, com os adultos $(96,12 \%)$, e o gênero feminino (58,25\%), representando a maioria dos pescadores (Tabela 1). A contribuição dos idosos na comunidade se dá na fabricação de apetrechos de pesca e/ou na renda da família por meio do benefício da aposentadoria. Com isso, deixam de utilizar os serviços da colônia Z-78 e de participar diretamente da captura do pescado, muitas vezes em função de problemas de saúde, ocasionados ou agravados pelo desgaste de uma vida de atividade pesqueira.

Tabela 1: Aspectos sociais de pescadores do município de Água Doce do Maranhão, Maranhão.

\begin{tabular}{ccc}
\hline Aspectos & Resposta & $\begin{array}{c}\text { Porcentagem } \\
\text { (Número de } \\
\text { Indivíduos/Total) }\end{array}$ \\
\hline \multirow{2}{*}{ Idade } & Jovens (18 a 24 anos) & $3,88 \%(04 / 103)$ \\
& Adultos (25 a 59 anos) & $96,12 \%(99 / 103)$ \\
\hline \multirow{2}{*}{ Gênero } & Feminino & $58,25 \%(60 / 103)$ \\
Cor/Raça & Masculino & $41,75 \%(43 / 103)$ \\
& Branco & $11,65 \%(12 / 103)$ \\
Estado Civil & Negro & $11,65 \%(12 / 103)$ \\
& Pardo & $76,70 \%(79 / 103)$ \\
\hline \multirow{2}{*}{ Filhos } & Solteiro & $19,42 \%(20 / 103)$ \\
& União Estável & $35,93 \%(37 / 103)$ \\
& Casado & $38,83 \%(40 / 103)$ \\
Educação & Divorciado & $2,91 \%(3 / 103)$ \\
& Viúvo & $2,91 \%(3 / 103)$ \\
\hline & Nenhum & $13,59 \%(14 / 103)$ \\
& 1 a 5 & $78,64 \%(81 / 103)$ \\
& 6 a 13 & $7,77 \%(8 / 103)$ \\
\hline & Ensino Fundamental Incompleto & $24,27 \%(25 / 103)$ \\
& Ensino Fundamental Completo & $52,43 \%(54 / 103)$ \\
& Ensino Médio Incompleto & $4,85 \%(5 / 103)$ \\
& Ensino Médio Completo & $6,80 \%(7 / 103)$ \\
\hline
\end{tabular}

Fonte: Elaborado pelos autores, 2020.

Em estudos realizados com comunidades pesqueiras da APA Delta do Parnaíba, como os de Cantanhêde et al. (2018), Nascimento et al. (2019) e Diniz et al. (2020), foi registrado o predomínio de adultos do gênero masculino. A predominância de homens com faixa etária entre 25 e 59, provavelmente deve estar relacionada ao fato da atividade de pesca artesanal não ser um atrativo entre os mais jovens, principalmente, em localidades próximas a grandes centros urbanos, onde a oferta de emprego e renda é maior (ARAÚJO et al., 2009; EVANGELISTA BARRETO, 2014).

A atuação das mulheres como pescadoras ocorre desde a captura até o tratamento do pescado para o consumo, facilitando o provimento de alimentação. Os benefícios sociais associados a essa atividade são um 
atrativo, o que para Façanha e Silva (2017), possibilitam uma maior contribuição da mulher na renda familiar, além da possibilidade de realizar a tarefa junto com o marido e outros familiares, desempenhando, portanto, papel fundamental para a pesca tradicional local. O predomínio da figura feminina na pesca também foi registrado por Meireles et al. (2017) na comunidade Passarinho em Araioses, no Maranhão, Oliveira et al. (2018) no litoral norte de São Paulo, Sousa et al. (2019) em Santarém do Pará e Rios (2019), na Bahia.

Quanto à cor/raça, 76,70 \% se declararam pardos, enquanto 11,65 \% brancos e negros, cada um. O termo "moreno" foi utilizado inicialmente tanto por pardos quanto por negros, que atribuíram essa cor mais à consequência da exposição ao sol. Para Evangelista Barreto et al. (2014), o elevado percentual de entrevistados se definindo como pardos, deve-se ao fato de, no item, ser levado em consideração a "cor da pele", e por ser auto declarativo, é um parâmetro de baixa precisão para uma eficaz categorização. A maioria dos entrevistados é casado (38,83 \%) ou tem união estável (35,93 \%) e 78,64\% tem de 1 a 5 filhos (Tabela 1). A falta de planejamento familiar e ausência de políticas públicas são observadas em comunidades de baixa renda levando ao número maior de filhos (EVANGELISTA BARRETO et al., 2014).

Dos pescadores não escolarizados $(24,27 \%)$, os homens representaram $60,0 \%$. A baixa escolaridade foi caracterizada principalmente pelo ensino fundamental incompleto $(52,43 \%)$ (Tabela 1$)$. O baixo grau de instrução na pesca pode estar relacionado à dificuldade de acesso e às condições de permanência na escola, ao desinteresse pela educação, à cultura familiar de passar o ofício da pesca para os filhos e às condições econômicas da família, que influenciam os filhos e/ou netos a realizarem a atividade de pesca mais cedo para complementar a renda ou mesmo sustentar a família (AMANAJÁS, 2018; CANTANHÊDE et al., 2018; PEREIRA et al., 2017; SILVA; D'INCAO, 2016). De forma complementar, a falta de compromisso pelos estudos pode ocorrer devido à falta de estímulo familiar, e mesmo interessados em estudar, sentem-se desestimulados, visto que as escolas, em sua maioria, não levam em consideração seu tempo, sua cultura, seus saberes e sua vida (SILVA; D'INCAO, 2016). A baixa escolaridade dos investigados também pode estar relacionada à deficiência na infraestrutura básica da educação na comunidade.

Os entrevistados moram na cidade de Água Doce há, no mínimo, nove anos. A maioria é natural do estado do Maranhão $(90,29 \%)$ e desses $75,27 \%$ são de Água Doce e 24,73 \% de munícipios vizinhos. Cantanhêde et al. (2018) registraram que os entrevistados de Cururupu, também no Maranhão, viviam na ilha por mais de 20 anos. O nível de conhecimento e familiaridade com o local onde se mora estão diretamente relacionados ao tempo vivido em uma área, ou seja, quanto maior o tempo, maior o nível de conhecimento e apego (CANTANHÊDE et al., 2018; SILVANO; BEGOSSI, 2012;).

Todos os pescadores possuem casa de alvenaria, própria (73,79\%), com mais de um tipo de aparelho como meio de informação, sendo a televisão $(97,09 \%)$ o principal meio, além do uso de celular $(66,99 \%)$, rádio $(55,34 \%)$ e 
computador (2,91\%), embora $1,94 \%$ não possuem nenhum dos aparelhos (Tabela 2). A utilização desses recursos é incentivada e proporcionada pelos programas assistencialistas, que permitem desde a doação de casas até a manutenção de condições básicas de subsistência.

Tabela 2. Aspectos de moradia de pescadores do município de Água Doce do Maranhão, Maranhão.

\begin{tabular}{|c|c|c|}
\hline Aspectos & Resposta & $\begin{array}{c}\text { Porcentagem } \\
\text { (Número de } \\
\text { Indivíduos/Total) }\end{array}$ \\
\hline \multirow{4}{*}{ Moradia } & Doada & $12,62 \% 13 / 103$ \\
\hline & Familiar & $11,65 \% 12 / 103$ \\
\hline & Herança & $1,94 \% 02 / 103$ \\
\hline & Própria & $73,79 \% 76 / 103$ \\
\hline \multirow{5}{*}{ Acesso à informação } & Sem acesso & $1,94 \% 2 / 103$ \\
\hline & Celular & $66,99 \% 69 / 103$ \\
\hline & Computador & $2,91 \% 03 / 103$ \\
\hline & Rádio & $55,34 \% 57 / 103$ \\
\hline & Televisão & $97,09 \% 100 / 103$ \\
\hline \multirow{3}{*}{ Abastecimento } & Encanada & $85,44 \% 88 / 103$ \\
\hline & Poço & $0,97 \% 01 / 103$ \\
\hline & Encanada e poço & $13,59 \% 14 / 103$ \\
\hline \multirow{2}{*}{ Cisterna } & Sim & $7,77 \% 08 / 103$ \\
\hline & Não & $92,23 \% 95 / 103$ \\
\hline \multirow{5}{*}{ Água para consumo } & Sem tratamento & $27,19 \% 28 / 103$ \\
\hline & Coada & $33,98 \%$ 35/103 \\
\hline & Fervida & $8,74 \% 09 / 103$ \\
\hline & Filtrada & $26,21 \% 27 / 103$ \\
\hline & Mineral & $3,88 \% 04 / 103$ \\
\hline \multirow{4}{*}{ Águas servidas } & Céu aberto & $34,95 \% 36 / 103$ \\
\hline & Fossa & $15,53 \% 16 / 103$ \\
\hline & Horta & $45,64 \% 47 / 103$ \\
\hline & Céu aberto/Fossa/Horta & $3,88 \% 04 / 103$ \\
\hline \multirow{3}{*}{ Esgoto } & Céu aberto & $1,94 \% 02 / 103$ \\
\hline & Fossa Negra & $77,67 \% 80 / 103$ \\
\hline & Fossa séptica & $20,39 \% 21 / 103$ \\
\hline \multirow{5}{*}{ Resíduos sólidos } & Céu aberto & $4,85 \% 05 / 103$ \\
\hline & Coleta pública & $56,31 \% 58 / 103$ \\
\hline & Enterra & $1,94 \% 02 / 103$ \\
\hline & Queima & $9,71 \% 10 / 103$ \\
\hline & Coleta pública/Enterra/Queima & $27,19 \% 28 / 103$ \\
\hline
\end{tabular}

Fonte: Elaborado pelos autores, 2020.

O abastecimento de água na sede do município é proveniente de poços com armazenamento em caixas d'água em alguns bairros da sede, visando à distribuição para a população. Dentre os entrevistados, $85,44 \%$ utilizam apenas água encanada, 13,59 \% também possuem poço e uma residência usa somente água de poço próprio. Ainda assim, 7,77\% armazenam água da chuva em cisternas ou tambores, principalmente para lavagem de roupas. A maior parcela dos pescadores $(33,98 \%)$ consome água coada com auxílio de 
um pano, 27,19 \% a utilizam direto da torneira, sem previamente realizar nenhum tratamento domiciliar, 26,21 \% filtram, 8,74 \% fervem e 3,88 \% fazem uso de água mineral (Tabela 2). No Maranhão $74 \%$ das sedes municipais são abastecidas exclusivamente por mananciais subterrâneos; as águas superficiais abastecem $21 \%$ dos municípios, enquanto $5 \%$ são abastecidos por ambas as fontes (ANA, 2010).

As águas servidas, por sua vez, são despejadas, em sua maioria, em hortas (45,64 \%), 34,95 \% a céu aberto, 15,53\% em fossas e 3,88\% combinam as três formas. Para destino das excretas 77,67 \% utilizam fossa negra, 20,39 \% fossa séptica e 1,94\% despejam a céu aberto (Tabela 2 ). No cenário nacional em torno de 99,4 milhões de pessoas $(47,7 \%)$ vivem sem condições básicas de coleta e tratamento de esgoto (COSTA; PINHEIRO, 2018). Na zona urbana do município de Água Doce do Maranhão, $89 \%$ da população utiliza fossa rudimentar, o que evidencia a ausência de infraestrutura para atender as necessidades de melhoria no saneamento básico, principalmente em relação ao esgotamento sanitário e possíveis contaminações dos mananciais subterrâneos, sendo um problema para a sociedade e um grande desafio para os governantes (PNSR, 2020; IMESC, 2016).

Em relação aos resíduos sólidos, a maioria dos entrevistados (56,31\%) utiliza o sistema de coleta pública, 9,71 \% queimam seus resíduos, 4,85\% despejam em céu aberto e 1,94 \% os enterram. Cerca de 27,19\% afirmam utilizar mais de uma forma de descarte do lixo produzido e, apesar de existir um sistema de coleta pública, a disposição final do lixo urbano não é realizada adequadamente em aterro sanitário. No Brasil, em várias localidades, o prazo para implementação de aterros sanitários (até 2014), bem como a extinção dos lixões existentes, não foi cumprido como determinado pela Política Nacional de Resíduos Sólidos - PNRS, lei $n^{\circ} 12.305 / 10$, o que pode causar, com a poluição ambiental, danos à saúde da população (ABRELPE, 2019).

Em relação às fontes geradoras de renda familiar, a pesca artesanal é a única para 53,40 \% dos entrevistados, 27,18 \% desenvolvem, em paralelo, atividades no comércio e $19,42 \%$ na prestação de serviços diversos como pedreiro, doméstica, vigia, secretária etc. (Tabela 3). Para 10,68 \% o pescado é utilizado para sua própria alimentação, enquanto para 48,54\% a venda do pescado gera, como renda principal ou complementar (em valores de reais para 2019), entre $R \$ 50,00$ e $R \$ 300,00$ reais e para 40,78\% entre $R \$ 301,00$ a $R \$ 1000,00$ reais (Tabela 3 ), destinados ao sustento de suas famílias.

A complementação da renda com outras atividades tem sido uma alternativa às dificuldades encontradas pelos pescadores na comercialização, o que para Evangelista Barreto et al. (2014) está relacionado com a quantidade do pescado capturado, que muitas vezes é suficiente apenas para a subsistência, justificando o baixo poder aquisitivo dos pescadores artesanais e a necessidade de outras fontes de renda. 
Tabela 3: Aspectos de renda de pescadores do município de Água Doce do Maranhão, Maranhão, no ano de 2019.

\begin{tabular}{ccc}
\hline Aspectos & Resposta & $\begin{array}{c}\text { Porcentagem } \\
\text { (Número de } \\
\text { Indivíduos/Total) }\end{array}$ \\
\hline \multirow{2}{*}{ Renda com a Pesca } & Nenhuma & $10,68 \% 11 / 103$ \\
& $50-300$ & $48,54 \% 50 / 103$ \\
Renda Secundária & $301-1000$ & $40,78 \% 42 / 103$ \\
& Nenhuma & $53,40 \% 55 / 103$ \\
Satisfação em ser pescador & Comércio & $27,18 \% 28 / 103$ \\
& Serviços & $19,42 \% 20 / 103$ \\
\hline \multirow{2}{*}{ Tipo de Embarcação } & Gosta & $64,08 \% 66 / 103$ \\
& Fonte de Renda & $14,56 \% 15 / 103$ \\
Origem da Embarcação & Alimentação & $6,80 \% 07 / 103$ \\
& Não satisfeito/Não teve opção & $14,56 \% 15 / 103$ \\
\hline
\end{tabular}

Fonte: Elaborado pelos autores, 2020.

Ao serem questionados sobre a importância da pesca para suas vidas, todos consideraram ser uma importante fonte de renda, alimentação e sustento. Os pescadores, em geral, sentem-se satisfeitos por exercerem essa profissão, justificando que gostam $(64,08 \%)$ e estão satisfeitos por ser uma fonte de renda $(14,56 \%)$ e de alimentação $(6,80 \%)$ (Tabela 3). É possível notar que o bem-estar gerado pela pesca vai além das dificuldades de se ter uma renda melhor. Para Cidreira Neto et al. (2019), as relações de trabalho e as interações socioambientais, presentes em todas as etapas da pesca, por vezes se intercruzam com o lazer, tornando a atividade prazerosa, diferente das formas tradicionais capitalistas de emprego.

O tipo de embarcação predominante nas pescarias é a canoa com motor rabeta $(82,52 \%)$, utilizada no sistema de parceria (55,34 \%), com a divisão dos gastos e lucros entre familiares, amigos e vizinhos. Fica evidente com as percepções dos pescadores que os motores ampliam as possibilidades na escolha dos pontos de pesca, pois variáveis ambientais (correntezas e ventos) e de espaço (distância e tempo) podem ser desconsideradas em suas tomadas de decisões. Para Zacarkim et al. (2017), o uso de barcos a motor é um importante investimento na atividade do pescador, uma vez que facilita sua locomoção até os locais de instalação das artes de pesca. Verifica-se, então, que a inserção de nova tecnologia na embarcação é percebida, principalmente, como redutora do esforço físico, embora requeira mais custos financeiros.

$\mathrm{Na}$ comunidade estudada, a compra dos apetrechos de pesca é geralmente realizada nas cidades de Água Doce e Tutóia, no Maranhão e em Parnaíba, no Piauí ou ainda fabricado pelos próprios pescadores. Os investigados relataram o uso de mais de um apetrecho de pesca (caçoeira, tarrafa, groseira, zangaria, linha, pulsa e landuá) pois, as técnicas de captura mudam de acordo com a espécie alvo, sendo a caçoeira a mais utilizada $(71,80$ 
\%). Zacarkim et al. (2017) e Amorim et al. (2019) também registraram a predominância na preferência da rede de emalhar (caçoeira), que é uma rede de espera, confeccionada com linha de nylon, chumbo e isopor, com flutuadores numa extremidade e pesos no lado oposto e possui formato retangular. $O$ interesse por redes de emalhar se deve ao fácil uso, baixo custo e, enquanto está afixada em um determinado ponto do ambiente aquático, dependendo do local de pesca e da espécie alvo, permite o uso de outro aparelho de pesca ou a realização de outras atividades produtivas (MARINHO; FARIA JUNIOR, 2020).

Entre os entrevistados $77,67 \%$ já receberam em algum momento o seguro defeso, que auxilia os pescadores durante o período de proteção à reprodução natural dos peixes (piracema) e 62,14 \% receberam outros benefícios do governo, como bolsa escola, bolsa família, vale gás, pensão vitalícia, cartão cidadão e auxílio-doença. Os rendimentos oriundos de transferências previdenciárias e assistenciais incentivam a sustentabilidade social, econômica e ambiental da atividade pesqueira, o que para Campos e Chaves (2016) revela acentuada importância principalmente para os que têm a pesca como único meio de subsistência. Porém, o recebimento de benefícios de forma indevida acarreta a cessação da condição de beneficiário. Tal situação, portanto, gera medo e desconfiança na comunidade dificultando, inclusive, a aplicação de pesquisas e fiscalização para o conhecimento sobre a real efetividade de políticas públicas (SECAP, 2019). Os subsídios gerados a partir das características socioeconômicas dos pescadores, se aplicados de forma efetiva em propostas que visem o bem coletivo, melhoram a qualidade de vida dos envolvidos e contribuem para valorizar o desenvolvimento da pesca artesanal na região.

A alimentação, a sobrevivência e o sustento de suas famílias foram os elementos usados pelos pescadores para definir a importância do rio Água Doce em suas vidas, evidenciando que existe um olhar de respeito e afetividade para com o rio. Contudo, observou-se a necessidade de discussões sobre questões ambientais entre os órgãos competentes, a colônia Z-78 e os próprios pescadores, para facilitar a gestão dos recursos naturais da região. Para Dictoro e Hanai (2016), a dependência, o valor dado e o sentimento de pertencimento ao local influenciam nas atitudes do pescador, auxiliando na conservação dos recursos aquáticos.

Quanto às atividades praticadas no rio, 30,10 \% o utilizam apenas para pesca e $22,33 \%$ para pesca e como via de acesso para locais de pesca mais distantes. Cerca de $15,53 \%$ utilizam o rio para pesca e lazer e 32,04 \% para pesca, lazer e via de acesso. Esses resultados corroboram com os apresentados por Rios (2019), que vê os locais com cais e/ou aglomeração de embarcações como pontos de busca por alimento, de renda, de cultura, de encontro, de conversas e de convívio social, em uma relação com a natureza, nutrindo laços de identificação, respeito e pertencimento. 
Dos investigados, 49,50 \% não têm conhecimento de atividades turísticas desenvolvidas na região, apesar dessas atividades existirem (MARANHÃO, 2012). O fato de os visitantes, geralmente, não serem estrangeiros ou não ter um perfil de visitantes que apenas consomem serviços, quase não criando vínculos com a localidade, fazem com que os moradores locais não percebam tais visitas como atividade turística. Embora o plano de turismo do estado do Maranhão contemple a região do Delta do rio Parnaíba, o turismo é divulgado e ofertado para uma população predominante externa (MARANHÃO, 2012; SANTOS; FERREIRA, 2016).

O período de maior movimentação de embarcações no rio Água Doce é durante a preamar $(79,6 \%)$, pois facilita a saída das embarcações do cais, devido à variação de maré $( \pm 3 m)$ na região (PEREIRA et al., 2016). Os entrevistados relataram que o aproveitamento da correnteza para chegar e voltar dos locais de pesca facilita a economia, seja de combustível ou de força física, porém outros fatores podem influenciar na escolha do horário de saída para pesca, como o tipo de pescado e o material a ser utilizado. Para Feitosa et al. (2019), o pescador artesanal atrela a sua vida ao tempo e à dinâmica do ambiente, ou seja, aprendeu durante o tempo a traduzir os processos e as espécies que habitam o ambiente e que estão condicionadas ao regime das marés e sazonalidade.

Em relação à qualidade da água do rio Água Doce, $83,50 \%$ dos pescadores consideram que é limpa e 16,50\% "sujas", embora 56,31\% considerem que há trechos onde há mais sujeira. Os pescadores acreditam que a sujeira é oriunda de lixos domésticos (sacos, garrafas etc.), resíduos de apetrechos de pesca, descarte de gasolina ou óleo usado na manutenção de motores, efluentes de viveiros de camarão e de folhas e madeiras caídas do mangue, encontrados principalmente nas margens do rio, nos igarapés, nas praias das ilhas, no cais da cidade e próximo aos viveiros de camarão.

Para $95,15 \%$ dos pescadores, a cor da água é o maior indicador de qualidade e sua mudança é notada durante os meses chuvosos $(84,47 \%)$, em períodos de maré grande ou de lançamento $(72,8 \%)$ e na preamar $(59,22 \%)$. Mudanças ao longo do tempo também foram observadas pelos pescadores na profundidade e largura do rio, principalmente, pela formação de coroas, o que pode indicar um processo de assoreamento no rio. A maioria $(54,37 \%)$ considera que a água estando mais "suja" facilita a captura de peixe, 31,70\% consideram a pesca melhor quando a água está mais "limpa", 14,56 \% não veem diferença ou atribui o resultado da pesca a outros fatores, como época do ano e tipo de pescaria. Souza et al. (2020), ao analisarem as características limnológicas do rio Água Doce observaram aumento nos valores de turbidez da água justamente durante a preamar e no período chuvoso, sendo a precipitação pluviométrica o principal fator determinante na dinâmica do rio.

Costa et al. (2017), ao estudarem a qualidade da água do rio Goiana, na Paraíba, reforçam a influência das chuvas na turbidez e cor da água, pois com aumento do fluxo de água ocorre o escoamento de partículas sólidas que são 
levadas para o canal principal do rio e a erosão das margens podem interferir na dispersão da luz solar na coluna d'água. Para Fernandes da Silva et al. (2018), a água mais barrenta/"suja”, aumenta a camuflagem do apetrecho e facilita a pesca para alguns tipos de pescado, como a Tainha (Mugil brasiliensis Agassiz, 1831).

Para $79,61 \%$ dos entrevistados, nos últimos anos houve diferença na quantidade de pescado capturado, associado ao uso de apetrechos como a "zangaria", que chega a possuir $20 \mathrm{~mm}$ de malha e dois quilômetros ou mais de rede de operação. Este apetrecho é proibido em outras regiões do país, porém é permitido em todo o litoral maranhense (com atividades suspensas de maio a agosto), pela Instrução Normativa no 39/04 do IBAMA. Diniz et al. (2020), destacaram que a problemática desse apetrecho de pesca está relacionada ao pequeno tamanho das malhas e a extensão das redes que capturam uma grande quantidade de fauna acompanhante.

As soluções propostas por 65,08 \% dos investigados, para melhorar a qualidade da água e a quantidade de pescado disponível, envolveram a conscientização dos pescadores em relação ao descarte do lixo doméstico, evitando sua chegada ao rio por lixiviação e ao uso de zangaria pelos pescadores locais e de municípios vizinhos, seja modificando o tamanho da malha do apetrecho ou proibindo seu uso. Além disso, propuseram o aumento da fiscalização pelo IBAMA, pela colônia Z-78 e pelos próprios pescadores.

É possível observar que há conhecimento empírico sobre a necessidade de não poluir o rio e de permitir a reprodução e crescimento dos animais. Apesar disso, os pescadores consideram ineficazes as atividades de fiscalização realizadas pelos órgãos ambientais (onde citam o IBAMA e a Secretaria de Estado do Meio Ambiente e Recursos Naturais-SEMA), porém nota-se o desconhecimento por parte desses atores, da Instrução Normativa no39/2004, que autoriza o uso de zangaria na região, exceto no período de defeso, o que justificaria a ausência de fiscais direcionados a esta prática. Cantanhedê et al. (2018) perceberam que em Curupuru, Maranhão, a maioria dos pescadores não se consideram responsáveis por problemas oriundos da atividade pesqueira, exceto quando são causadas por pescadores de comunidades vizinhas. Essas atitudes reforçam a necessidade de programas e projetos de Educação Ambiental, que alertem sobre as consequências da pesca insustentável, desenvolvendo ações que possam contribuir para a manutenção da qualidade do rio e dos estoques pesqueiros da região.

\section{Conclusão}

A atividade de pesca no rio Água Doce se mostrou pouco atrativa para os jovens e as mulheres se apresentaram como grandes contribuintes para o sustento familiar. As condições básicas de moradia são alicerçadas, principalmente, pela renda gerada com a pesca, mas também por atividades secundárias e benefícios governamentais. 
O rio Água Doce tem grande importância para o desenvolvimento da região e das famílias de pescadores e, embora seja encontrado lixo descartado irregularmente no ambiente, os pescadores consideram a água do rio de boa qualidade, ressaltando mudanças de coloração apenas em alguns períodos, associados ao fluxo de marés e épocas do ano, o que influencia diretamente na escolha das técnicas e apetrechos de pesca utilizados.

A fiscalização e a conscientização são tidas pelos pescadores como ferramentas eficazes para garantir o uso sustentável dos recursos aquáticos. Assim, sugere-se o desenvolvimento de projetos e/ou programas de Educação Ambiental que mobilizem a comunidade quanto à manutenção da qualidade ambiental do rio Água Doce, o conhecimento da legislação e a fiscalização entre os próprios pescadores no uso de apetrechos de pesca mais sustentáveis em relação à captura.

\section{Agradecimentos}

Os autores agradecem à FAPEPI, pela concessão de bolsa à primeira autora e à comunidade de pescadores da colônia Z-78 do município de Água Doce do Maranhão, Maranhão.

\section{Referências}

ABRELPE. Panorama dos Resíduos Sólidos no Brasil - 2018/2019. 2019. Disponível em: http://abrelpe.org.br/download-panorama-2018-2019/. Acesso em: 15 ago. 2020.

ANA- AGÊNCIA NACIONAL DE ÁGUAS. Atlas Brasil: abastecimento urbano de água: panorama nacional. 2010. Disponível em: http://atlas.ana.gov.br /Atlas/downloads/atlas/Resumo\%20Executivo/Atlas\%20Brasil\%20-\%20Volume \%201\%20-\%20Panorama\%20Nacional.pdf. Acesso em: 10 ago. 2020.

AMANAJÁS, V. V. V. Pesca e perfil socioeconômico dos pescadores artesanais da fronteira setentrional do Brasil: a comunidade pesqueira de Oiapoque, Amapá. Confins. v.1, n. 37, p. 1-9, 2018.

AMORIM, J. C. et al. Entre a terra e a água: a pesca e o conhecimento etnoictiológico dos pescadores artesanais. Ethnoscientia, v.4, n.1, p. 1-18, 2019.

APPOLINÁRIO, F. Metodologia da ciência: filosofia e prática da pesquisa. $2^{a}$ ed. São Paulo. Cengage Learning. 2012.

ARAÚJO, A. R. R. et al. Gestão da pesca de Mytella charruana (D'ORBIGNY, 1846) no litoral do estado de Sergipe: indicadores de sustentabilidade. Revista Brasileira de Engenharia de Pesca, v. 4, n. 2, p. 56-72, 2009.

BARBETTA, P. A. Estatística aplicada às ciências sociais. $7^{a}$ ed. Editora UFSC: Florianópolis. 2011.

BARBOSA, A. R. et al. Abordagem etnoherpetológica de São José da Mata-Paraíba-Brasil. Revista de Biologia e Ciências da Terra, v. 7, n. 2, p. 1-8, 2007. 
CAMPOS, A. G.; CHAVES, J. V. Perfil laboral dos pescadores artesanais no Brasil: insumos para o programa seguro defeso. Mercado de Trabalho. v.1, n.60, p. 1-12, 2016.

CANTANHÊDE, L. G. et al. Environmental perception of fishermen: use and conservation of fisheries resources. Biota Neotropica, v. 18, n. 4, p. 1-10, 2018.

CIDREIRA NETO, I. R. G.; FRAGOSO, M. L. B.; RODRIGUES, G. G. Pesca artesanal do marisco no litoral paraibano: relações socioambientais e tecnologias sociais. Revista de Geografia (Recife), v. 36, n. 1, p. 1-13, 2019.

CORREIA, F. L. F.; GOMES, É. R.; NUNES, O. O.; LOPES, J. B. F. Projeto cadastro de fontes de abastecimento por água subterrânea: estado do Maranhão: relatório diagnóstico do município de Água Doce do Maranhão, Serviço Geológico do Brasil. 2011.

COSTA, C. R. et al. Interannual water quality changes at the head of a tropical estuary. Environmental Monitoring and Assessment, v. 189, n. 12, p. 628, 2017.

COSTA, R. N. P.; PINHEIRO, E. M. O cenário do saneamento básico no Brasil. Educação Ambiental em Ação, v. 66, n.1, p. 1-26, 2018.

DICTORO, V. P.; HANAI, F. Y. Análise da relação homem-água: a percepção ambiental dos moradores locais de cachoeira de Emas-SP, bacia hidrográfica do rio Mogi-guaçu. Raega-O Espaço Geográfico em Análise, v. 36, n.1, p. 92 120, 2016.

DICTORO, V. P.; GALVÃO, D. F.; HANAI, F. Y. O estudo das representações sociais e da percepção ambiental como instrumentos de análise das relações humanas com a água. Ambiente \& Educação, v. 21, n. 1, p. 232-251, 2016.

DINIZ, A. L. C. et al. O uso multiplo da área de pesca do município de Raposa, Maranhão/Brasil/The multiple use of the fishing area in the municipality of Raposa, Maranhão/Brazil. Brazilian Journal of Development, v. 6, n. 2, p. 6999-7010, 2020.

EVANGELISTA, N. S. B. et al. Indicadores socioeconômicos e percepção ambiental de pescadores em São Francisco do Conde, Bahia. Boletim do Instituto de Pesca, v. 40, n. 3, p. 459-470, 2018.

FAÇANHA, C. L.; SILVA, C. J. Caracterização da Colônia de Pescadores Z2 de Cáceres em Mato Grosso. Interações (Campo Grande), v. 18, n. 1, p. 129136, 2017.

FEITOSA, L. L. A.; BARROS, M. C.; ALMEIDA, Z. S. Manejo tradicional da pesca na Área de Proteção Ambiental do Delta das Américas. Revista Brasileira De Educação Ambiental, v. 14, n. 4, p. 305-322, 2019.

FERNANDES DA SILVA, R. S.; MARTINS, V. L.; GIRÃO, O. Evaluación preliminar del conocimiento etnoclimático y etnogeomorfológico de los pescadores de la costa del municipio de Goiana - estado de Pernambuco, Brasil. Revista Geográfica de América Central, v.1, n.60, p. 301 - 328, 2018. 
FOGACA, F. H. S. et al. Vida na água: contribuições da Embrapa. Embrapa. Brasília- DF. 2018. Disponível em: https://www.alice.cnptia.embrapa.br/ bitstream/doc/1090716/1/ODS14.pdf. Acesso em: 25 ago. 2020.

GARCIA, M. R.; FURTADO, M. L. A comunidade de pescadores tradicionais de Carnaubeiras-Araioses-MA: Percepções socioambientais e aspectos culturais. Espaço e Cultura, v. 1, n. 40, p. 181-202, 2016.

IBGE- INSTITUTO BRASILEIRO DE GEOGRAFIA E ESTATÍSTICA. Censo Demográfico 2010, Área territorial brasileira. 2011. Disponível em: https://biblioteca.ibge.gov.br/visualizacao/periodicos/93/cd 2010 caracteristica s populacao domicilios.pdf. Acesso em: 13 ago. 2020.

INSTITUTO MARANHENSE DE ESTUDOS SOCIOECONÔMICOS E CARTOGRÁFICOS. Plano Mais IDH: Diagnóstico Avançado: Água Doce do Maranhão. 2016. Disponível em: http://imesc.ma.gov.br/atlas/ Home/diagnostico. Acesso em: 10 ago. 2020.

MARANHÃO. Plano Estratégico de Turismo do Estado do Maranhão: plano maior 2020. Disponível em: http://portal.antaq.gov.br/wp-content/uploads/ 2016/12/Maranh\%C3\%A3o-\%C3\%9Anico-\%E2\%80\%93-O-Plano-Maior-2020Jurandir-Ferro-do-Lago-Filho.pdf. Acesso em: 15 ago. 2020.

MARINHO, J. C.; FARIA JÚNIOR, C. H. Diagnóstico da atividade pesqueira praticada por pescadores filiados a colônia de pescadores Z-66, do município de Curuá-PA./Diagnosis of fishing activity practiced by fishermen affiliated with fishermen colony Z-66, from the city of Curuá-PA. Brazilian Journal of Development, v. 6, n. 2, p. 8780-8794, 2020.

MEIRELES, M. P. A. et al. Características da pesca artesanal realizada na comunidade Passarrinho/llha das Canárias/MA. Gaia Scientia, v. 11, n. 3, p. 12-26, 2017.

NASCIMENTO, F. C. A.; BRAGA, C. C.; ARAÚJO, F. R. C. D. Análise Estatística dos Eventos Secos e Chuvosos de Precipitação do Estado do Maranhão. Revista Brasileira de Meteorologia, v. 32, n. 3, p. 375-386, 2017.

NASCIMENTO, M. G. P.; MEIRELES, V. J. S.; ANDRADE, I. M.; BARROS, R. F. M. Etnobotânica em uma comunidade de pescadores artesanais na área de proteção ambiental (APA), Delta do Parnaíba, Piauí, Brasil. Educação Ambiental em Ação, v.18, n.68, p. 1-15, 2019.

OLIVEIRA, N. R.; SANTOS, C. R.; TURRA, A. Percepção ambiental como subsídio para gestão costeira da Baía do Araçá, Litoral Norte do Estado de São Paulo, Brasil. Desenvolvimento e Meio Ambiente, v. 44, n. 1, p. 140-163, 2018.

PEREIRA, L. C. C. et al. Maranhão beach systems, including the human impact on São Luís Beaches. In: Brazilian Beach Systems. Springer, Cham. p.125152, 2016.

PEREIRA, T. J. F. et al. Extrativismo de mariscos na ilha do Maranhão (MA): implicações ecológicas e socioeconômicas. Revista de Políticas Públicas, v. 21, n. 2, p. 831-853, 2017.

revista brasileira educação ambiental 
PHILLIPS, O.; GENTRY, A. H. The useful woody plants of Tambopata, Peru, II: further statistical tests of hypotheses in quantitative ethnobotany. Economic Botany, v. 47, n.1, p. 15-32, 1993.

PROGRAMA NACIONAL DE SANEAMENTO RURAL. PNSR em construção. Funasa, Brasília, 2020. Disponível em: http://pnsr.desa.ufmg.br/pnsr/. Acesso em: 18 ago. 2020.

RAMALHO, C. W. N. Mestria da pesca: cultura de um ofício. Etnográfica. Revista do Centro em Rede de Investigação em Antropologia, v. 24, n.2, 2019.

RIOS, K. A. N. " No rio e no mar, pescadores na luta": a pesca artesanal no Estado da Bahia, Brasil. Um cenário de contradições e resistência. Revista del CESLA. International Latin American Studies Review, v.1, n. 23, p. 281-299, 2019.

SILVIA, A. M.; LUCENI, $H$. Mulheres na atividade pesqueira no Brasil. Campos dos Goytacazes, RJ. Editora EDUENF, p. 1-368, 2019.

SANTOS, H. G. et al. Sistema brasileiro de classificação de solos. Brasília, DF: Embrapa, 2018.

SANTOS, K. F. L.; ARAÚJO, A. J. F. A produção e consumo do espaço turístico no município de Tutóia (MARANHÃO). Espaço e Cultura, v.1, n. 40, p. 113-132, 2016.

SECRETARIA DE AVALIAÇÃO, PLANEJAMENTO, ENERGIA E LOTERIA. Relatório de avaliação de gastos diretos: Avaliação executiva do seguro defeso. 2019. Disponível em: Ministério da Economia. Disponível em: https://www.gov.br/economia/pt-br/centrais-de-conteudo/publicacoes/notasinformativas/2019/relatorio segurodefeso.pdf. Acesso em: 09 ago. 2020.

SILVA, R. G.; D'INCAO, F. Perfil socioeconômico e laboral dos pescadores artesanais de camarão-rosa no complexo estuarino de Tramandaí (RS), Brasil. Boletim do Instituto de Pesca, v. 42, n. 2, p. 387-401, 2018.

SILVA, M. C. Estuários-critérios para uma classificação ambiental. Revista Brasileira de Recursos Hídricos, v. 5, n. 1, p. 25-35, 2000.

SILVANO, R. A.M.; BEGOSSI, A. Fishermen's local ecological knowledge on Southeastern Brazilian coastal fishes: contributions to research, conservation, and management. Neotropical Ichthyology, v. 10, n. 1, p. 133-147, 2012.

SOUSA, W. L. et al. Protagonismo socioeconômico das pescadoras artesanais do bairro Pérola do Maicá, em Santarém Pará. Revista Ciências da Sociedade, v. 2, n. 4, p. 143-161, 2018.

SOUZA, G. S.; NASCIMENTO, M. G. P.; LINS, R. P. M.; ANDRADE, I. M. Caracterização limnológica do rio Água Doce, Município de Água Doce do Maranhão. Manuscrito em preparação. 2020.

ZACARKIM, C. E.; DUTRA, F. M.; OLIVEIRA, L. C. Perfil dos pescadores da foz do rio Araguaia, Brasil. Extensio: Revista Eletrônica de Extensão, v. 14, n. 25, p. 27-44, 2017. 